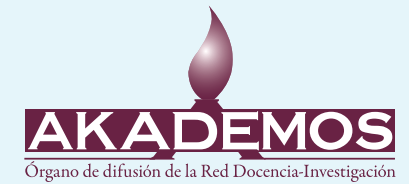

ISSN: 1995-4743

Vol. $2, n^{\circ} 33$

AKADEMOS es una revista semestral. De amplio espacio editorial, para la publicación de trabajos inéditos de investigación, artículos de análisis, reseñas y opinión, en los distintos tópicos de las ciencias, la tecnología, las artes y la cultura.

\title{
Matriz de contenidos y ejes transversales para la educación artística
}

\section{(Propuesta de trabajo)}

Marta Eugenia Valle Contreras

Investigadora del Centro de Investigaciones en Ciencias y Humanidades, $\mathrm{CICH}$ de la Universidad Dr. José Matías Delgado. Dra. en Educación por la Universidad de Granada, España. Ejecuta el Programa de Investigaciones para el Fomento de la Educación Artística desde el 2008.

mevallec@ujmd.edu.sv

\section{Resumen}

La asignatura de Educación Artística es una oportunidad potente en el currículo nacional para favorecer una educación integral e integradora. Aquí se adelanta, tomada de una experiencia reciente de formación docente en educación artística, una herramienta que ayuda al docente a transversalizar los contenidos de dicha asignatura en la enseñanza básica. En esta matriz de referencia para el docente, la herramienta retoma los contenidos de artes visuales incluidos en el Programa de Estudios de la asignatura de Educación Artística, aquellos otros ejes transversales que forman parte del currículo y otras convenciones internacionales, como por ejemplo los Objetivos de Desarrollo Sostenible 2030 (ONU) y también retoma los contenidos de las otras asignaturas de los Programas de Estudio de Primero y Sexto Grado que sugieren rutas para la transversalización de la asignatura de Educación Artística en el currículo de enseñanza básica.

Palabras clave: educación artística, educación, arte, transversalización, formación docente 


\section{Abstract}

Art Education is a powerful opportunity in the national curriculum to favor integral and integrative education. Here, we share a reference tool for teachers to help them consider Art Education complementary relationships with other Subjects across the primary education curriculum in El Salvador. This supports art education teacher training by its creation and proposing the use of this kind of organizing matrixes, which includes in one single chart Art Education contents (in this case those of visual arts) and the transversal education axes of the national curriculum, as well as other international conventions such as the Objectives of Sustainable Development 2030 (UN), and also selected contents of the other Subjects that are part of the First and Sixth Grade Curriculum. This in order to help teachers to visualize in a single chart possible routes for art education across curriculum as a strategy to inspire holistic and integrative art education experiences and projects.

Keywords: art education, education, art, teacher training

En el marco del proceso de formación docente en educación artística con la planta docente y personal de apoyo del Centro Escolar Cantón El Tránsito, en Talnique, La Libertad, que ocupa desde principios del 2017 al equipo de investigación correspondiente del Centro de Investigaciones en Ciencias y Humanidades (CICH) de la Universidad Dr.
José Matias Delgado; la Matriz de Trabajo que se presenta a continuación constituye una herramienta para la planificación didáctica de la asignatura de Educación Artística en la enseñanza básica.

Es una herramienta que ayuda al docente a considerar posibles "rutas" para transversalizar los contenidos de Educación Artística, en este caso los contenidos del área de artes visuales, del Programa de Estudios de la asignatura, con aquellos otros ejes que forman parte del currículo y con otras convenciones internacionales, como los Objetivos de Desarrollo Sostenible 2030, con los que se debe enriquecer las sesiones de Educación Artística en el entorno escolar para favorecer una formación del alumnado de manera holística, integradora, transformadora, desde las experiencias significativas en educación artística, estética y cultural que diseñe el profesorado.

Por lo tanto, esta matriz se publica como una propuesta inspiradora para que los docentes que imparten Educación Artística hagan este ejercicio, buscando en el cuadro contenidos afines o complementarios que transversalmente pueden relacionarse a los de "Artes Visuales" (Columna 1 en la matriz de trabajo) que se quieren desarrollar en la secuencia pedagógica, con el mismo fin de enriquecer la mirada integradora que aporta la asignatura de Educación Artística.

Cabe señalar que este ejercicio no agota las posibilidades de transversalización de los programas de estudio de las otras asignaturas con la asignatura de Educación Artística; 
no se incluyen todos los contenidos posibles ni tampoco los de cada asignatura del currículo de enseñanza básica. Además, en cada columna se incluyen diferentes tipos de contenidos (conceptuales, procedimentales y actitudinales), notas tomadas de los preliminares en los Programas de Estudio de Primer y Sexto grado (MINED, 2008) y notas de la facilitadora del Módulo de artes visuales hechas durante la mencionada formación docente en educación artística. El profesorado encontrará otros más. 

MATRIZ DE CONTENIDOS Y EJES TRANSVERSALES PARA LA EDUCACIÓN ARTÍSTICA

\section{Herramienta de apoyo para que el docente realice un ejercicio de transversalización de la Educación Artística a partir de}

los Programas de Estudio de Primer Grado del MINED (2008) (*Ver reseña del ejercicio)

Por: Marta Eugenia Valle Contreras (2018).

Proyecto de Formación Docente en Educación Artística (2017-2020): Módulo de Artes Visuales.

Centro de Investigaciones en Ciencias y Humanidades, CICH, Universidad Dr. José Matías Delgado / Un centro escolar de La Libertad.

\begin{tabular}{|c|c|c|}
\hline $\begin{array}{l}\text { 1. Contenidos de artes visuales } \\
\text { del Programa de Estudio de Educación Artística } \\
\text { de Primer Grado (MINED, 2008) }\end{array}$ & $\begin{array}{l}\text { 2. Contenidos que se refieren } \\
\text { al Patrimonio cultural }\end{array}$ & $\begin{array}{l}\text { 3. Selección de contenidos de Lenguaje } \\
\text { del Programa (MINED, 2008) } \\
\text { de Primer grado (Para el ejercicio) }\end{array}$ \\
\hline $\begin{array}{l}1 .^{\circ} \text { grado } \\
\text { Unidad } 1 . \text { Nos comunicamos con el Arte }\end{array}$ & \multirow{3}{*}{$\begin{array}{l}\text { **(Tradiciones, celebraciones y conmemoraciones } \\
\text { comunitarias, como: Fiestas patronales, el día dedicado } \\
\text { a un producto o cultivo emblemático de la zona como } \\
\text { el café, el maíz, el henequén y la jarcia, la cerámica local, } \\
\text { entre otros). }\end{array}$} & $\begin{array}{l}1 .^{\circ} \text { grado } \\
\text { Unidad 1: Nos conocemos }\end{array}$ \\
\hline $\begin{array}{l}\text { Principales tipos de papel para manualidades: de diario, } \\
\text { crespón, bond, carulina y manila. }\end{array}$ & & $\begin{array}{l}\text { Construcción identitaria a partir de la escritura de su } \\
\text { nombre y al vincular su dirección al reconocimiento del } \\
\text { entorno: aula, escuela, comunidad, país. (Sugerencia de } \\
\text { las maestras participantes en esta formación docente). }\end{array}$ \\
\hline $\begin{array}{l}\text { Técnica del rasgado, bruñido, retorcido, plegado y } \\
\text { recortado. }\end{array}$ & & Ambientación en el aula y normas de convivencia. \\
\hline Tarjetas para el día de la amistad. & Noción de palabra escrita. & Noción de palabra escrita. \\
\hline $\begin{array}{l}\text { Líneas rectas y onduladas en dirección horizontal, vertical } \\
\text { o inclinada trazadas a mano alzada. }\end{array}$ & & $\begin{array}{l}\text { Textos de tradición oral: canciones, rondas y juegos que } \\
\text { contengan reiteraciones, ritmos y rimas marcados. }\end{array}$ \\
\hline $\begin{array}{l}\text { Dibujo de características físicas de personajes de } \\
\text { narraciones. }\end{array}$ & & $\begin{array}{l}\text { 1. }{ }^{\circ} \text { grado } \\
\text { Unidad 2: El secreto de los libros }\end{array}$ \\
\hline Colores primarios: amarillo, azul y rojo. & & Sonidos onomatopéyicos. \\
\hline Dibujo del contenido de canciones. & & $\begin{array}{l}1 .^{\circ} \text { grado } \\
\text { Unidad 3: Somos cinco }\end{array}$ \\
\hline $\begin{array}{l}1 .^{\circ} \text { grado } \\
\text { Unidad 2. Aprendamos con el Arte }\end{array}$ & & Las vocales. \\
\hline $\begin{array}{l}\text { Adornos decorativos para el día de la familia: } \\
\text { mamá, papá, otros. }\end{array}$ & & Letra de imprenta y ligada. \\
\hline
\end{tabular}

**A Aparecen entre paréntesis notas de la autora o aportes de las maestras participantes en la formación. 


\begin{tabular}{|c|c|c|}
\hline $\begin{array}{l}\text { 1. Contenidos de artes visuales } \\
\text { del Programa de Estudio de Educación Artística } \\
\text { de Primer Grado (MINED, 2008) }\end{array}$ & $\begin{array}{l}\text { 2. Contenidos que se refieren } \\
\text { al Patrimonio cultural }\end{array}$ & $\begin{array}{l}\text { 3. Selección de contenidos de Lenguaje } \\
\text { del Programa (MINED, 2008) } \\
\text { de Primer grado (Para el ejercicio) }\end{array}$ \\
\hline $\begin{array}{l}\text { Materiales naturales y artificiales que se pueden teñir: } \\
\text { cascarones de huevo, vasos descartables, semillas, palitos } \\
\text { de paletas, piedrecillas, botellas, papel, otros. }\end{array}$ & & $\begin{array}{l}1 .^{\circ} \text { grado } \\
\text { Unidad 4: Observemos los animales }\end{array}$ \\
\hline $\begin{array}{l}\text { Recursos para teñir y decorar figuras: pegamento, tijeras } \\
\text { sin puntas, colorante dulce, yeso mojado, témperas, otros. }\end{array}$ & & $\begin{array}{l}\text { Comprensión oral del contenido literal de poemas y rimas } \\
\text { que escucha. }\end{array}$ \\
\hline $\begin{array}{l}\text { Artesanías decorativas: selección de una artesanía } \\
\text { de la zona. }\end{array}$ & $\begin{array}{l}\text { Artesanías decorativas: selección de una artesanía } \\
\text { de la zona. }\end{array}$ & Poemas y rimas. \\
\hline Manualidades para representar la naturaleza. & & $\begin{array}{l}1 .{ }^{\circ} \text { grado } \\
\text { Unidad } 5: \text { ¿Qué hacen las familias? }\end{array}$ \\
\hline Materiales del contexto para decorar figuras. & Materiales del contexto para decorar figuras. & $\begin{array}{l}\text { Lectura en voz alta de palabrasque contienen las letras } n \text {, } \\
\text { t, r, con apoyo de dibujos. } \\
\text { Reconocimiento de oraciones, palabras, sílabas, sonidos } \\
\text { y letras, formadas con las consonantes } n, t \text {, r, al escuchar y } \\
\text { leer poemas, adivinanzas y situaciones familiares. }\end{array}$ \\
\hline $\begin{array}{l}1 .^{\circ} \text { grado } \\
\text { Unidad } 2 . \text { Aprendamos con el Arte }\end{array}$ & & $\begin{array}{l}1 .{ }^{\circ} \text { grado } \\
\text { Unidad } 7: \text { Compartimos en la comunidad }\end{array}$ \\
\hline \multirow[t]{2}{*}{ Técnica del enguatado para hacer títeres. } & & Diálogo. \\
\hline & & $\begin{array}{l}1 .{ }^{\circ} \text { grado } \\
\text { Unidad 8: Historias divertidas }\end{array}$ \\
\hline $\begin{array}{l}\text { Materiales adecuados para hilvanar: lana, hilo, papel } \\
\text { retorcido. }\end{array}$ & & Tarjetas de invitación. \\
\hline Rompecabezas. & & $\begin{array}{l}10^{\circ} \text { grado } \\
\text { Unidad 9: Descubramos cosas interesantes }\end{array}$ \\
\hline Modelaje de figuras humanas con bolitas y rollos. & & Recetas de cocina. \\
\hline \multicolumn{3}{|l|}{ Técnica de plegado. } \\
\hline Manualidades decorativas: gallardetes y tapetes. & & \\
\hline
\end{tabular}


4. Selección de contenidos de Matemática del Programa de Primer grado (Para el ejercicio)

$10^{\circ}$ grado

Unidad $1: ¡ Q u e ́$ divertida la matemática!

Dimensiones en las personas, animales y objetos:

Grande, pequeño, tan grande como, tan pequeño como, grueso, delgado, gordo, flaco.

Tonos de los objetos: Claro, oscuro.

\section{Ubicación espacial:}

Cerca, lejos, izquierda, derecha,arriba, abajo, dentro, fuera, entre, sobre, detrás, al lado, frente a, en medio, junto, contiguo, en relación a un punto de referencia.

con

\section{Posiciones:}

Vertical, horizontal, inclinado.
5. Contenidos del Programa de Ciencias,

Salud y Medio Ambiente de Primer grado (Seleccionados para el ejercicio)

\section{$1 .^{\circ}$ grado}

Unidad 1: Anatomía y fisiología animal y vegetal

Los seres vivos, objetos y materiales del entorno. Semejanzas y diferencias externas (piel y extremidades) entre animales: aves, mamíferos, peces e insectos.

Semejanza y diferencias de las plantas del entorno por su tamaño: hierbas, arbustos y árboles.

Semejanzas y diferencias entre animales y plantas: formas de alimentación, desplazamiento o movimiento y medio en el que viven.

\section{$1 .^{\circ}$ grado}

Unidad 2: Sensaciones que recibimos

Incluye estos contenidos: Características de materiales y objetos del entorno (materia inerte) por su color, olor, forma y sabor. Estímulos percibidos por los órganos de los sentidos.

Respeto y aceptación de su cuerpo y el de los demás.
6. Unidades y bloques de contenido del Programa de Estudios Sociales de Primer grado (Seleccionados para el ejercicio)

\section{$1 .^{\circ}$ grado}

Unidad 1: El Medio que nos rodea

Cualidades de sí mismo y de los compañeros, compañeras y docente. Noción de espacio. Relaciones espaciales. Orientación espacial. Ubicación del centro escolar, funciones en el centro escolar.

\section{$1 .^{\circ}$ grado}

Unidad 2: Nosotros en el medio

Conservación del paisaje geográfico de la localidad.

Intervención de los seres humanos en el ambiente.

La vivienda, las necesidades básicas de la familia.

Instrumentos, aparatos y enseres de la tecnología

utilizados el hogar, centro escolar y localidad. Uso apropiado y manejo responsable.

Normas de seguridad vial al conducirse por la vía pública. 
4. Selección de contenidos de Matemática del Programa de Primer grado (Para el ejercicio)

\section{Tiempo:}

Día, noche, antes, después, ayer, hoy, mañana.

Días de la semana, mes, año.

El calendario.

\section{Características externas de los objetos:}

Colecciones de objetos.

\section{Series: de objetos y figuras.}

Observación e identificación del patrón de una serie. Determinación del patrón y complementación en una serie de objetos o dibujos.

Construcción de series a partir de patrones.

Características de los objetos por su uso o utilidad:

Relación uno a uno. Identificación del uso o utilidad de objetos y/o dibujos. Identificación de la relación entre objetos o dibujos afines según su uso.
5. Contenidos del Programa de Ciencias,

Salud y Medio Ambiente de Primer grado (Seleccionados para el ejercicio)

\section{$1 .^{\circ}$ grado}

Unidad $4^{* *}$ : Alimentos que comemos y bebemos

Objetivo: Describir las características, la preparación y

el comercio de los alimentos, observando su color, olor,

sabor y condiciones higiénicas para nutrirse, mantenerse

saludable y evitar enfermedades como la fiebre tifoidea.

\section{$10^{\circ}$ grado}

Unidad 5**: Nuestra amiga el agua

Objetivo: Describir los usos cotidianos y estados físicos del agua, identificando y explicando las características del agua potable para evitar enfermedades relacionadas con la deficiente práctica de hábitos higiénicos y el consumo de agua contaminada.

\section{$10^{\circ}$ grado}

Unidad 6**: La Tierra, nuestro hogar

Objetivos: Identificar a la Tierra como un elemento del cielo, describiendo y representando sus componentes naturales para valorarla como hogar del ser humano y de otros seres vivos.

Contenidos: Todos los contenidos.

\section{$1 .^{\circ}$ grado}

Unidad 4: Nosotros convivimos

Los derechos y los deberes.
6. Unidades y bloques de contenido del Programa de Estudios Sociales de Primer grado (Seleccionados para el ejercicio)

\section{$1 .^{\circ}$ grado}

Bloque 1: El medio geográfico y sociocultural de la localidad

\section{$10^{\circ}$ grado}

Bloque 2: El conocimiento social y afectivo-moral del niño y la niña en la escuela, familia y localidad

\section{$10^{\circ}$ grado}

Unidad 3: La sociedad en que vivimos

El centro escolar. La familia. Importancia. Organización de actividades que se realizan en el centro escolar, hogar y localidad.

\section{** En toda la unidad hay mucho potencial para transversalizar con Educación artística.}


4. Selección de contenidos de Matemática del Programa de Primer grado (Para el ejercicio)

$10^{\circ}$ grado

Unidad 6: ¡Descubramos las formas!

\section{Cuerpos geométricos:}

Noción de esfera (pelota), sólido rectangular/cubo (caja), cilindro (lata). Superficies: planas y curvas. Dimensiones:

largo, ancho y alto.

\section{$10^{\circ}$ grado}

Unidad 10: ¡Comparemos y Compremos!

5. Contenidos del Programa de Ciencias,

Salud y Medio Ambiente de Primer grado (Seleccionados para el ejercicio)

Instituciones. Normas de convivencia social en el hogar, centro escolar y localidad.

\section{Longitud:}

Magnitudes, medidas arbitrarias y medidas no

convencionales (corporales): jeme, pulgada, cuarta,

brazada, paso, pie.

\section{Noción de peso:}

Balanza.
6. Unidades y bloques de contenido del Programa

de Estudios Sociales de Primer grado (Seleccionados para el ejercicio)

\section{$1 .^{\circ}$ grado}

Unidad 4: Nosotros convivimos

Los derechos y los deberes. Instituciones. Normas de convivencia social en el hogar, centro escolar y localidad.

\section{$10^{\circ}$ grado}

Unidad 5: El tiempo

Nociones de tiempo, de continuidad temporal. Pasado personal, familiar y escolar.

\section{$10^{\circ}$ grado}

Unidad 6: Somos nuestro pasado

Noción de cambio. Personajes históricos. Identidad nacional. Bloque 3: Desarrollo histórico de la localidad. 


\begin{tabular}{|c|c|c|}
\hline $\begin{array}{l}\text { 7. Selección de contenidos conceptuales } \\
\text { de Estudios Sociales del Programa } \\
\text { de Primer grado (Para el ejercicio) }\end{array}$ & $\begin{array}{l}\text { 8. Selección de contenidos procedimentales } \\
\text { de Estudios Sociales del Programa } \\
\text { de Primer grado (Para el ejercicio) }\end{array}$ & $\begin{array}{l}\text { 9. Contenidos disciplinares de las Artes Visuales en } \\
\text { la educación artística (Efland, Marín, Hernández, } \\
\text { Freedmand, Maeso, Toro, entre otros contemporaneos) } \\
\text { (Lista completa por publicarse) }\end{array}$ \\
\hline $\begin{array}{l}1 .^{\circ} \text { grado } \\
\text { Unidad } 1: \text { El Medio que nos rodea }\end{array}$ & $\begin{array}{l}\text { Representación de los objetos desde diferentes } \\
\text { perspectivas: vistos desde el techo, desde arriba, desde } \\
\text { el piso, desde abajo, de un lado. } \\
\text { Explicación y trazado de cuadrícula para la elaboración } \\
\text { del plano de la localidad. } \\
\text { Utilización de puntos de referencia para orientarse en } \\
\text { el espacio, mediante juegos. }\end{array}$ & $\begin{array}{l}\text { 1. Las técnicas, medios y procesos artísticos abordados } \\
\text { como lenguajes: }\end{array}$ \\
\hline $\begin{array}{l}\text { Nombre, características y cualidades de sí mismo, de sus } \\
\text { compañeros y compañeras, maestros y maestras. Noción de } \\
\text { espacio. }\end{array}$ & $\begin{array}{l}\text { Trabajos y funciones del personal que labora en el } \\
\text { centro escolar. }\end{array}$ & Los elementos de las artes visuales. \\
\hline $\begin{array}{l}\text { Relaciones espaciales entre los objetos (dentro-fuera, próximo- } \\
\text { lejano, al medio, al final). }\end{array}$ & $\begin{array}{l}\text { Uso apropiado y manejo responsable de la tecnología: } \\
\text { microondas, televisores, grabadoras, proyectores, } \\
\text { discos compactos, videos, entre otros. } \\
\text { Vías de comunicación: calles,avenidas, aceras, carril y } \\
\text { cuneta; y medios de transporte de la localidad. }\end{array}$ & \\
\hline El centro escolar, dependencias y ubicación. & & \\
\hline
\end{tabular}




\begin{tabular}{|c|c|c|}
\hline $\begin{array}{l}\text { 7. Selección de contenidos conceptuales } \\
\text { de Estudios Sociales del Programa } \\
\text { de Primer grado (Para el ejercicio) }\end{array}$ & $\begin{array}{l}\text { 8. Selección de contenidos procedimentales } \\
\text { de Estudios Sociales del Programa } \\
\text { de Primer grado (Para el ejercicio) }\end{array}$ & $\begin{array}{l}\text { 9. Contenidos disciplinares de las Artes Visuales en } \\
\text { la educación artística (Efland, Marín, Hernández, } \\
\text { Freedmand, Maeso, Toro, entre otros contemporaneos) } \\
\text { (Lista completa por publicarse) }\end{array}$ \\
\hline \multicolumn{3}{|l|}{ La vivienda. Ubicación. } \\
\hline \multicolumn{3}{|l|}{$\begin{array}{l}\text { Dependencias básicas de la vivienda y sus enseres. El paisaje } \\
\text { geográfico: elementos naturales (agua, relieve, flora, fauna, } \\
\text { clima). }\end{array}$} \\
\hline \multicolumn{3}{|l|}{$\begin{array}{l}\text { Noción de ícono y símbolo como representación de la realidad } \\
\text { geográfica en el plano de la localidad. }\end{array}$} \\
\hline \multicolumn{3}{|l|}{$\begin{array}{l}1 .^{\circ} \text { grado } \\
\text { Unidad } 2 . \text { El paisaje geográfico }\end{array}$} \\
\hline \multicolumn{3}{|l|}{$\begin{array}{l}\text { "Elementos sociales (vivienda, servicios, vías de } \\
\text { comunicación,sitios históricos,entre otros) y los usos del } \\
\text { espacio. El trabajo que realizan las personas de la localidad } \\
\text { y los beneficios que proporcionan en la satisfacción de las } \\
\text { necesidades básicas (alimentación, vivienda, salud, educación, } \\
\text { ocio.)" }\end{array}$} \\
\hline \multirow{2}{*}{\multicolumn{3}{|c|}{$\begin{array}{l}\text { Señales de tránsito: el semáforo. } \\
\text { Organización urbana y rural: las calles, avenidas,caminos } \\
\text { vecinales, veredas y atajos de la localidad, y en torno a la casa y } \\
\text { a la escuela. }\end{array}$}} \\
\hline & & \\
\hline \multicolumn{3}{|l|}{$\begin{array}{l}\text { "Gestión para la reducción del riesgo de los efectos adversos } \\
\text { causados por la intervención del ser humano } \\
\text { en el ambiente." }\end{array}$} \\
\hline \multicolumn{3}{|l|}{$\begin{array}{l}\text { Medios de comunicación social: periódicos, teléfono, radio, } \\
\text { televisión, Internet. }\end{array}$} \\
\hline
\end{tabular}




\begin{tabular}{|c|c|c|}
\hline $\begin{array}{l}\text { 7. Selección de contenidos conceptuales } \\
\text { de Estudios Sociales del Programa } \\
\text { de Primer grado (Para el ejercicio) }\end{array}$ & $\begin{array}{l}\text { 8. Selección de contenidos procedimentales } \\
\text { de Estudios Sociales del Programa } \\
\text { de Primer grado (Para el ejercicio) }\end{array}$ & $\begin{array}{l}\text { 9. Contenidos disciplinares de las Artes Visuales en } \\
\text { la educación artística (Efland, Marín, Hernández, } \\
\text { Freedmand, Maeso, Toro, entre otros contemporaneos) } \\
\text { (Lista completa por publicarse) }\end{array}$ \\
\hline \multicolumn{3}{|l|}{ La familia. Características. } \\
\hline \multicolumn{3}{|l|}{$\begin{array}{l}1 .^{\circ} \text { grado } \\
\text { Unidad } 4 . \text { Nosotros convivimos. }\end{array}$} \\
\hline \multicolumn{3}{|l|}{$\begin{array}{l}\text { Medios de comunicación social: periódicos, teléfono, } \\
\text { radio, televisión, Internet. }\end{array}$} \\
\hline \multicolumn{3}{|l|}{ Derechos de la niñez. } \\
\hline \multicolumn{3}{|l|}{$\begin{array}{l}1 .^{\circ} \text { grado } \\
\text { Unidad } 5 . \text { El Tiempo }\end{array}$} \\
\hline \multicolumn{3}{|l|}{$\begin{array}{l}\text { Noción de pasado personal, familiar y escolar. } \\
\text { Noción de historia y de fuentes históricas. }\end{array}$} \\
\hline \multicolumn{2}{|l|}{$\begin{array}{l}\text { Historia de la fundación y el nombre del centro escolar } \\
\text { y la localidad. }\end{array}$} & \\
\hline \multicolumn{3}{|l|}{$\begin{array}{l}1 .^{\circ} \text { grado } \\
\text { Unidad } 6: \text { Noción de cambio }\end{array}$} \\
\hline $\begin{array}{l}\text { "Cambios cotidianos y de observación de la naturaleza. } \\
\text { Velocidad de los cambios: unos elementos permanecen } \\
\text { mientras otros cambian." }\end{array}$ & & \\
\hline
\end{tabular}




\begin{tabular}{|c|c|c|c|c|}
\hline \multicolumn{2}{|c|}{$\begin{array}{l}\text { 10. Educación Biocéntrica } \\
\text { (Lista completa por publicarse) }\end{array}$} & $\begin{array}{l}\text { 11. Educación artística contemporánea } \\
\text { (Lista completa por publicarse): }\end{array}$ & $\begin{array}{l}\text { 12. Agenda } 2030 \text { para el Desarrollo } \\
\text { Sostenible (ONU, 2015) } \\
\text { (Ver lista completa en } \\
\text { https://es.unesco.org/sdgs) }\end{array}$ & $\begin{array}{l}\text { 13. Fundamentos Curriculares de la } \\
\text { Educación Nacional: Ejes Transversales } \\
\text { (MINED, 1999, p. 77) }\end{array}$ \\
\hline \multicolumn{2}{|c|}{$\begin{array}{l}\text { (Áreas y subáreas en Educación Biocéntrica. } \\
\text { Por Nélida Pérez [2017], Maestra Didácta de } \\
\text { Biodanza) (Lista completa por publicarse) }\end{array}$} & $\begin{array}{l}\text { Construir cohesión social a través de la } \\
\text { Educación Artística. } \\
\text { Enfoque de la cultura visual (Hernández), } \\
\text { expresionista, pragmática (Aguirre). }\end{array}$ & $\begin{array}{l}\text { Objetivo 1: } \\
\text { Poner fin a la pobreza en todas sus formas } \\
\text { en todo el mundo. }\end{array}$ & \multirow[t]{2}{*}{$\begin{array}{l}\text { Educación en Derechos Humanos. } \\
\text { Educación para la salud. } \\
\text { Educación preventiva integral. } \\
\text { Educación ambiental. } \\
\text { Educación en población. }\end{array}$} \\
\hline Área. & Subáreas. & $\begin{array}{l}\text { Comprender la identidad. Agenda de países } \\
\text { en desarrollo (África, Colombia, Costa Rica). } \\
\text { Proteger nuestra herencia cultural diversa. } \\
\text { Construir responsabilidad social y } \\
\text { ciudadanía }\end{array}$ & $\begin{array}{l}\text { Objetivo 2: } \\
\text { Poner fin al hambre, lograr la seguridad } \\
\text { alimentaria y la mejora de la nutrición y } \\
\text { promover la agricultura sostenible. }\end{array}$ & \\
\hline \multirow[t]{4}{*}{ Ciudadanía. } & Colectivo-cooperativismo. & & $\begin{array}{l}\text { Objetivo 3: } \\
\text { Garantizar una vida sana y promover el } \\
\text { bienestar en todas las edades. }\end{array}$ & \\
\hline & $\begin{array}{l}\text { Ética del encuentro y del } \\
\text { cuidado del otro. }\end{array}$ & & & \\
\hline & Conciencia crítica. & & & \\
\hline & Pedagogía de la pregunta. & & & \\
\hline
\end{tabular}





\section{MATRIZ DE CONTENIDOS Y EJES TRANSVERSALES PARA LA EDUCACIÓN ARTÍSTICA}

Herramienta de apoyo para que el docente realice un ejercicio de transversalización de la asignatura de Educación Artística a partir de los Programas de Estudio de Sexto Grado del MINED (2008) (Ver reseña del ejercicio)

Por: Marta Eugenia Valle Contreras (2018)

Proyecto de Formación Docente en Educación Artística (2017-2020): Módulo de Artes Visuales.

Centro de Investigaciones en Ciencias y Humanidades, $\mathrm{CICH}$, Universidad Dr. José Matías Delgado / Un centro escolar de La Libertad

\begin{tabular}{|c|c|c|}
\hline $\begin{array}{l}\text { 1. Contenidos de artes visuales del Programa } \\
\text { de Estudio de Sexto Grado de la asignatura de } \\
\text { Educación Artística (MINED, 2008) }\end{array}$ & $\begin{array}{l}\text { 2. Contenidos que se refieren al Patrimonio cultural } \\
\text { (Del Programa de estudio de Sexto Grado, } \\
\text { MINED, 2008) }\end{array}$ & $\begin{array}{l}\text { 3. Selección de contenidos de Lenguaje } \\
\text { del Programa de Sexto Grado (MINED, 2008) } \\
\text { (Para el ejercicio) }\end{array}$ \\
\hline $\begin{array}{l}6 .^{\circ} \text { grado } \\
\text { Unidad 1. Expresión artística y nuestro entorno }\end{array}$ & $\begin{array}{l}\text { ***(Tradiciones, celebraciones y conmemoraciones } \\
\text { comunitarias, como: Fiestas patronales, el día dedicado } \\
\text { a un producto o cultivo emblemático de la zona como } \\
\text { el café, el maíz, el henequén y la jarcia, la cerámica local, } \\
\text { entre otros). }\end{array}$ & $\begin{array}{l}6 .^{\circ} \text { grado } \\
\text { Unidad 1: Nos comunicamos }\end{array}$ \\
\hline El arte como registro de la cotidianidad y la historia. & El arte como registro de la cotidianidad y la historia. & $\begin{array}{l}\text { Comprende el registro coloquial y culto o especializado; } \\
\text { además del propósito, destinatario y lugar de la acción } \\
\text { comunicativa. } \\
\text { Algunos libros de referencia y consulta: diccionario, } \\
\text { enciclopedias y guía telefónica. }\end{array}$ \\
\hline $\begin{array}{l}\text { El campo visual, ángulo de visión y punto de vista en las } \\
\text { historietas. }\end{array}$ & & $\begin{array}{l}6 .^{\circ} \text { grado } \\
\text { Unidad 2: Recordemos }\end{array}$ \\
\hline La proporción entre el todo y las partes. & & $\begin{array}{l}\text { Lectura y escritura de diferentes textos informativos } \\
\text { atendiendo a la estructura, características y función. }\end{array}$ \\
\hline El retrato y el busto. & & $\begin{array}{l}\text { 6. } .^{\circ} \text { grado } \\
\text { Unidad 5: La Magia de Narrar }\end{array}$ \\
\hline
\end{tabular}

***Aparecen entre paréntesis notas de la autora o aportes de las maestras participantes en la formación. 
1. Contenidos de artes visuales del Programa de Estudio de Sexto Grado de la asignatura de Educación Artística (MINED, 2008)
2. Contenidos que se refieren al Patrimonio cultural

(Del Programa de estudio de Sexto Grado, MINED, 2008)
3. Selección de contenidos de Lenguaje del Programa de Sexto Grado (MINED, 2008) (Para el ejercicio)

Estilos pictóricos de retratos.

Colores luz, colores pigmento y complementarios.

La simplificación gráfica para el diseño de una marca.

(Recuperación del Patrimonio oral : Ver la Unidad 6 del Programa de Estudio de Lenguaje de Sexto Grado).

(Reconocimiento del aporte sociocultural a través del

tiempo de las artes y de los artistas locales, regionales e

internacionales)

(Ubicación de sitios de interés cultural).

En esta unidad se estudia la estructura y elaboración de textos instruccionales diversos como: instrucciones para experimentos sencillos y manualidades; así como el periódico mural, el recibo, el cheque.

En relación con estos textos, se ven contenidos gramaticales y ortográficos.

\section{$6 .^{\circ}$ grado}

Unidad 6: Apreciemos la poesía

Se leen, memorizan y declaman poemas con la dicción y entonación correctas y también se estudia la estructura de los mismos (soneto), tipos de rima para conocerlos mejor y poder escribir algunos, como parte de su propia creación. El conocimiento y uso de figuras literarias como el adjetivo epíteto, así como contenidos gramaticales y de ortografía. Lectura de bombas, como muestra del ingenio e imaginación popular y escritura de éstas, según modelos.

\section{$6 .^{\circ}$ grado}

Unidad 7: Me divierto con las caricaturas

\section{$6 .^{\circ}$ grado}

Unidad 2: Exploremos el arte en el tiempo

Esta unidad tiene como objetivo estudiar la interpretación y producción de caricaturas, señales de tránsito y afiches. Algunos temas lingüísticos como los adverbios de duda y modo. Además, las palabras homófonas, antónimas y homógrafas.

Unidad 8. Nuestro mundo informativo 
1. Contenidos de artes visuales del Programa de Estudio de Sexto Grado de la asignatura de Educación Artística (MINED, 2008)

El textil para contar historias: el aplique.

Campo sensorial y conocimiento del entorno. Exploración y comparación de imágenes, sonidos, texturas, olores y sabores que requieran mayor concentración para su percepción.

\section{La vida cotidiana en un libro de artista.}

La creación de objetos en el Diseño Industrial.

El mosaico: elaboración de un mural.

\section{6. ${ }^{\circ}$ grado}

Unidad 3: Culturas y tecnologías en el arte

\section{$6 .^{\circ}$ grado \\ Unidad 3: Culturas y tecnologías en el arte}

Modelado con alambre.

Realización de un collage utilizando un software de dibujo digital.

La imagen fotográfica para registrar secuencias.
2. Contenidos que se refieren al Patrimonio cultural

(Del Programa de estudio de Sexto Grado, MINED, 2008)

3. Selección de contenidos de Lenguaje del Programa de Sexto Grado (MINED, 2008) (Para el ejercicio)

a autobiografía.

Relato histórico.

Relato histórico.

\section{La crónica.}

Organizadores gráficos de la información: mapas conceptuales. 


\begin{tabular}{|c|c|c|}
\hline $\begin{array}{l}\text { 4. Selección de contenidos de Matemática } \\
\text { del Programa de Sexto Grado (MINED, 2008) } \\
\text { (Para el ejercicio) }\end{array}$ & $\begin{array}{l}\text { 5. Selección de contenidos del Programa de Ciencias, } \\
\text { Salud y Medio Ambiente de Sexto Grado } \\
\text { (Seleccionados para el ejercicio) }\end{array}$ & $\begin{array}{l}\text { 6. Unidades y bloques de contenido del Programa de } \\
\text { Estudios Sociales de Sexto Grado (MINED, 2008) } \\
\text { (Seleccionados para el ejercicio) }\end{array}$ \\
\hline $\begin{array}{l}6 .^{\circ} \text { grado } \\
\text { Unidad 10: Conozcamos sistemas antiguos de } \\
\text { numeración }\end{array}$ & $\begin{array}{l}6 .^{\circ} \text { grado } \\
\text { Unidad } 1: \text { Sostén y movimiento }\end{array}$ & $\begin{array}{l}6 .^{\circ} \text { grado } \\
\text { Unidad } 1 \text { : El Continente en el que vivimos }\end{array}$ \\
\hline $\begin{array}{l}\text { Símbolos básicos y reglas de escritura de los sistemas } \\
\text { de numeración maya y romano. Conversiones entre } \\
\text { números mayas o romanos y números decimales. }\end{array}$ & $\begin{array}{l}\text { Sistema muscular. Diferentes tipos de fracturas. Ventajas } \\
\text { de las máquinas simples y compuestas. Ventajas y } \\
\text { desventajas de los avances tecnológicos en las máquinas. } \\
\text { Noción de movimiento y velocidad. Medición de } \\
\text { velocidad, distancia y tiempo. }\end{array}$ & $\begin{array}{l}\text { Ubicación geográfica de América a partir de puntos } \\
\text { cardinales y coordenadas geográficas. Ventajas y } \\
\text { desventajas de la ubicación, su perfil geográfico, } \\
\text { problemas limítrofes, relieves y el clima. Regiones y } \\
\text { paisajes geográficos y la sismicidad. }\end{array}$ \\
\hline $\begin{array}{l}\text { 6. }{ }^{\circ} \text { grado } \\
\text { Unidad 2: Tracemos figuras }\end{array}$ & $\begin{array}{l}6 .^{\circ} \text { grado } \\
\text { Unidad } 2 . \text { Nuestra amiga el agua }\end{array}$ & $\begin{array}{l}6 .^{\circ} \text { grado } \\
\text { Unidad 2: Recursos naturales }\end{array}$ \\
\hline $\begin{array}{l}\text { Suma de los ángulos internos de un polígono regular. } \\
\text { Simetría axial, rotacional con respecto a un eje y } \\
\text { rotacional entre sí. } \\
\text { Trazos y traslaciones de figuras en un plano. }\end{array}$ & $\begin{array}{l}6 .^{\circ} \text { grado } \\
\text { Unidad } 4 \text { : Previniendo accidentes y riesgos }\end{array}$ & $\begin{array}{l}\text { Nuestro tesoro: recursos naturales y su aprovechamiento. } \\
\text { Hidrografía y beneficios. El suelo, importancia. Población } \\
\text { y demandas al medio ambiente. Contaminación de } \\
\text { ríos, lagos y lagunas, formas de evitarlo. Inundaciones } \\
\text { y deslizamientos y daños que provocan. Marco legal } \\
\text { nacional e internacional para la protección del medio } \\
\text { ambiente. }\end{array}$ \\
\hline $\begin{array}{l}\text { 6. }{ }^{\circ} \text { grado } \\
\text { Unidad 5: Calculemos áreas }\end{array}$ & $\begin{array}{l}\text { El microscopio y algunos organismos unicelulares. Noción } \\
\text { de célula. }\end{array}$ & $\begin{array}{l}6 .^{\circ} \text { grado } \\
\text { Unidad 3: Así vivimos las americanas y los americanos }\end{array}$ \\
\hline $\begin{array}{l}6 .^{\circ} \text { grado } \\
\text { Unidad 7: Construyamos sólidos geométricos y } \\
\text { encontremos el volumen }\end{array}$ & $\begin{array}{l}6 .^{\circ} \text { grado } \\
\text { Unidad 5: El mundo físico que nos rodea }\end{array}$ & $\begin{array}{l}\text { Principales sectores productivos de América, la vida } \\
\text { urbana y rural, cooperativismo y trabajo cooperativo, } \\
\text { comunicación y desarrollo en América: redes viales, vías } \\
\text { férreas, puertos y aeropuertos, medios de transporte y } \\
\text { comunicación, señales de transito, marco legal vial, } \\
\text { la familia: sus funciones, la convivencia familiar y la } \\
\text { planificación de metas personales a corto y mediano } \\
\text { plazo. }\end{array}$ \\
\hline
\end{tabular}


4. Selección de contenidos de Matemática del Programa de Sexto Grado (MINED, 2008) (Para el ejercicio)

\section{$6 .^{\circ}$ grado}

Unidad 7: Construyamos sólidos geométricos y

encontremos el volumen.

\section{$6 .^{\circ}$ grado}

Unidad 9: Utilicemos otras medidas
5. Selección de contenidos del Programa de Ciencias, Salud y Medio Ambiente de Sexto Grado (Seleccionados para el ejercicio)

\section{$6 .^{\circ}$ grado}

Unidad 6: La Tierra, nuestro gran hogar

Distribución de los seres vivos en el planeta Tierra de

acuerdo al clima. Las estaciones, equinoccios y solsticios en el planeta Tierra y su influencia en los seres vivos.

Características y especies representantes de algunos reinos de la naturaleza: animal, vegetal y fungi. Especies animales y vegetales en peligro de extinción.

Tipos de suelo: arcillosos, aluviales, andisoles y regosoles.

Ventajas del compostaje.

\section{6. ${ }^{\circ}$ grado}

Unidad 7: Previniendo enfermedades
6. Unidades y bloques de contenido del Programa de Estudios Sociales de Sexto Grado (MINED, 2008) (Seleccionados para el ejercicio)

\section{$6 .^{\circ}$ grado}

Unidad 5: La identidad de América a través de la realidad histórica

La identidad de América a

través de la realidad histórica. Primeros pobladores de América: la cultura Maya, Azteca, Inca y Chibcha y su legado cultural, el patrimonio cultural,

descubrimiento, conquista y colonización, la colonización de América, los movimientos de independencia, los hechos ocurridos entre 1840 y 1992, ideales y aportes de destacados personajes en América.

\section{$6 .^{\circ}$ grado}

Unidad 6: La identidad de América a través de la realidad histórica

Unidad 6: Continuidad y cambio entre las sociedades pasadas y presentes. Hechos y cambios históricos ocu rridos en el período (1930-1979) 


\begin{tabular}{|c|c|c|c|c|c|}
\hline $\begin{array}{l}\text { 9. Contenidos disciplinares } \\
\text { de las Artes Visuales en } \\
\text { la educación artística } \\
\text { (Efland, Marín, Hernández, } \\
\text { Freedmand, Maeso, Toro, } \\
\text { entre otros contemporáneos) } \\
\text { (Lista completa por } \\
\text { publicarse) }\end{array}$ & \multicolumn{2}{|c|}{$\begin{array}{l}\text { 10. Educación Biocéntrica } \\
\text { (Lista completa por publicarse) }\end{array}$} & $\begin{array}{l}\text { 11. Educación artística } \\
\text { contemporánea } \\
\text { (Lista completa por publicarse): }\end{array}$ & $\begin{array}{l}\text { 12. Agenda } 2030 \text { para el } \\
\text { Desarrollo Sostenible (ONU, } \\
\text { 2015) (Ver lista completa en } \\
\text { https://es.unesco.org/sdgs) }\end{array}$ & $\begin{array}{l}\text { 13. Fundamentos Curriculares de } \\
\text { la Educación Nacional: } \\
\text { Ejes Transversales } \\
\text { (MINED, 1999, p. 77) }\end{array}$ \\
\hline $\begin{array}{l}\text { Las técnicas, medios y } \\
\text { procesos artísticos abordados } \\
\text { como lenguajes }\end{array}$ & \multicolumn{2}{|c|}{$\begin{array}{l}\text { (Áreas y subáreas en } \\
\text { Educación Biocéntrica. } \\
\text { Por Nélida Pérez [2017], Maestra } \\
\text { Didácta de Biodanza) (Lista } \\
\text { completa por publicarse) }\end{array}$} & $\begin{array}{l}\text { Construir cohesión social a través } \\
\text { de la Educación Artística. } \\
\text { Enfoque de la cultura visual } \\
\text { (Hernández), expresionista, } \\
\text { pragmática (Aguirre). }\end{array}$ & $\begin{array}{l}\text { Objetivo 1: } \\
\text { Poner fin a la pobreza en todas sus } \\
\text { formas en todo el mundo. }\end{array}$ & $\begin{array}{l}\text { Educación en Derechos Humanos. } \\
\text { Educación para la salud. } \\
\text { Educación preventiva integral. } \\
\text { Educación ambiental. } \\
\text { Educación en población }\end{array}$ \\
\hline $\begin{array}{l}\text { Los elementos de las artes } \\
\text { visuales. }\end{array}$ & Área & Subáreas & $\begin{array}{l}\text { Comprender la identidad. Agenda } \\
\text { de países en desarrollo (África, } \\
\text { Colombia, Costa Rica). } \\
\text { Proteger nuestra herencia cultural } \\
\text { diversa. } \\
\text { Construir responsabilidad social y } \\
\text { ciudadanía }\end{array}$ & $\begin{array}{l}\text { Objetivo 2: } \\
\text { Poner fin al hambre, lograr la } \\
\text { seguridad alimentaria y la mejora } \\
\text { de la nutrición y promover la } \\
\text { agricultura sostenible. }\end{array}$ & \\
\hline $\begin{array}{l}\text { Técnicas, materiales y } \\
\text { procesos para la expresión bi y } \\
\text { tridimensional: }\end{array}$ & Ciudadanía & $\begin{array}{l}\text { Colectivo } \\
\text {-cooperativismo. }\end{array}$ & & $\begin{array}{l}\text { Objetivo 3: } \\
\text { Garantizar una vida sana y } \\
\text { promover el bienestar en todas } \\
\text { las edades. }\end{array}$ & \\
\hline Procesos de creación en dibujo. & \multicolumn{2}{|c|}{$\begin{array}{l}\text { Ética del encuentro y del cuidado } \\
\text { del otro. }\end{array}$} & & & \\
\hline $\begin{array}{l}\text { Procesos de creación en la } \\
\text { pintura. }\end{array}$ & \multicolumn{2}{|c|}{ Conciencia crítica } & & & \\
\hline La Escultura. & \multicolumn{2}{|c|}{ Pedagogía de la pregunta } & & & \\
\hline
\end{tabular}

